\title{
PEMBELAJARAN UNTUK MASYARAKAT MENGENAI KEBENCANAAN GEOLOGI MELALUI KONSEP MODIFIKASI PRA (PARTICIPATORY RURAL APPRAISAL)
}

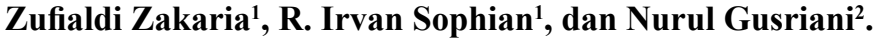 \\ ${ }^{1}$ Departemen Geologi Terapan, Fakultas Teknik Geologi, Universitas Padjadjaran \\ ${ }^{2}$ Departemen Matematika, Fakultas Matematika dan Ilmu Pengetahuan Alam, Universitas Padjadjaran \\ E-mail: zufialdi.zakaria@unpad.ac.id
}

\begin{abstract}
ABSTRAK. Wilayah Indonesia memiliki bencana geologis yang lengkap, yaitu gempa bumi, letusan gunung berapi, tsunami dan gerakan tanah. Dalam upaya memperkuat kapasitas masyarakat untuk menghadapi bencana, belajar tentang bencana geologis diperlukan. Agar pembelajaran dapat dicapai dengan cepat dan tepat sasaran, sebuah metode digunakan yaitu dengan cara memodifikasi konsep Participatory Rural Appraisal (PRA). Kegiatan belajar dilakukan dalam sebuah acara di Bale Desa Hegarmanah. Desa Hegarmanah adalah ibu kota Kecamatan Jatinangor. Peserta terdiri atas perwakilan masyarakat dari masing-masing Rukun Warga di desa dengan berbagai profesi, ada guru, ibu rumah tangga, karyawan, dan staf desa. Kegiatan ini dibantu oleh beberapa siswa yang mengikuti KKN. Pemberi materi pembelajaran adalah dosen pengawas lapangan. Hasil kegiatan menunjukkan perubahan signifikan. Ini dinilai dari pengetahuan sebelum dan sesudah aktivitas yang diketahui dari hasil tes sebelum dan sesudah pelaksanaan kegiatan seminar, konseling dan pembelajaran. Berdasarkan analisis, hanya ada $9 \%$ pada pertanyaan kesembilan yang tidak sesuai target, yaitu mengenai pengetahuan dari beberapa aplikasi Android untuk bahaya geologi yang dapat dipasang pada smartphone peserta. Ini karena peserta tidak membawa ponsel seluler yang kompatibel dengan sistem ponsel cerdas Android. Untuk melaksanakan kegiatan dalam bentuk seminar dengan konseling dan pembelajaran seperti acara ini, persyaratan untuk peserta dapat disampaikan terlebih dahulu di surat undangan. Manfaat atau kegunaan dari hal-hal yang dibuat dalam acara ini dapat disampaikan dalam undangan sehingga kegiatan sesuai dan tepat sasaran.
\end{abstract}

Kata kunci: Pembelajaran; kapasitas komunitas; modifikasi PRA; smartphone

\begin{abstract}
Indonesia territory has the complete geological disasters, namely earthquakes, volcanic eruptions, tsunami and earth movements. In an effort to strengthen the capacity of the community to deal with disasters, learning about geological disaster is required. In order for learning to be achieved quickly and on target, a method is used through the concept of Participatory Rural Appraisal (PRA) modification. Learning activities are carried out in an event in Bale Desa Hegarmanah at Hegarmanah village. Hegarmanah village is the capital of Jatinangor Sub-district. Participants consisted of community representatives from each of the Rukun Warga in the village with various professions, there were teachers, housewives, employees, and village staff. The activity was assisted by several students participating in the KKN (Kuliah Kerja Nyata). The learning material giver is a field supervisor lecturer. The results of the activities show significant changes. This was assessed from the knowledge before and after the activity which was known from the results of the tests before and after the implementation of the seminar, counseling and learning activities. Based on analysis, there only were 9\% on the ninth question that was not on target, namely regarding the knowledge of some Android applications for geological hazard that could be installed on the participant's smartphone. This is due to participant's not carrying a cellular handphones that are compatible with Android smartphone systems. To carry out activities in the form of seminars with counseling and learning like this event, the requirements for participants can be submitted beforehand in the invitation letter. The benefits or uses of the things that are made in these event can be conveyed in the invitation so that the activities are appropriate and on target.
\end{abstract}

Key words: Learning; community capacity; modification of PRA; smartphone

\section{PENDAHULUAN}

Dalam ilmu geologi, konsep Tektonik Lempeng sudah berkembang sejak awal abad 20, dan menjadi Konsep Global Tektonik Lempeng sekitar tahun 1970an. Permukaan bumi terbagi menjadi beberapa lapisan dari permukaan luar sampai inti bumi. Permukaan bumi terluar adalah kerak samudera dan kerak benua yang merupakan lempeng-lempeng tektonik. Lempeng-lempeng tersebut dinamis karena saling bergerak. Wilayah Indonesia sendiri merupakan wilayah tumbukan dari beberapa lempeng tektonik dunia. Di Indonesia bagian barat, terdapat tumbukan antara dua lempeng, yaitu lempeng Eurasia di utara dan lempeng Indo Australia di selatan. Sedangkan di Indonesia bagian timur, terdapat tumbukan tiga lempeng tektonik yaitu lempeng-lempeng Eurasia, Indo-Australia, dan Pasifik. Zona dari lempeng-lempeng tektonik ini merupakan wilayah yang kaya akan sumber mineral \& energi, tetapi juga kaya akan potensi bencana geologi (Zakaria, 2007).

Beberapa kejadian yang termasuk bencana geologi, yaitu: gerakan tanah (longsor dan gerakan tanah lainnya), letusan gunungapi, gempabumi, dan tsunami (BNPB, 2017). Bencana geologi tersebut menyebar di berbagai daerah di wilayah Indonesia. Gerakan tanah (longsor) berhubungan dengan wilayah berkemiringan atau lerenglereng. Bencana longsor merupakan salah satu peristiwa alam yang paling umum terjadi di Indonesia, terutama dalam waktu musim hujan (Fauzielly et al., 2018). Letusan gunungapi berhubungan dengan pusatpusat letusan gunung. Gempabumi berhubungan dengan pergerakan lempeng tektonik, patahan aktif atau getaran letusan gunungapi. Tsunami berhubungan dengan pusat gempabumi di bawah permukaan laut.

Sehubungan dengan hal tersebut di atas, maka dibutuhkan mitigasi bencana, pengurangan risiko bencana, 
dan perkuatan kapasitas masyarakat dalam menghadapi bencana. Menurut Undang-undang no. 24 tahun 2007 tentang Penanggulangan Bencana (Anonim, 2017), mitigasi bencana adalah serangkaian upaya untuk meng-urangi risiko bencana, baik melalui pembangunan fisik maupun penyadaran dan peningkatan kemampuan meng-hadapi ancaman bencana. Oleh sebab itu, dalam mitigasi bencana diperlukan cara-cara atau upaya mencegah, mengurangi, dan mengatasi keadaan sebelum bencana, saat kejadian bencana, dan pasca bencana. Salah satu cara adalah melalui Pengurangan Risiko Bencana dengan memberdayakan kapasitas masyarakat.

Peningkatkan kapasitas dan kemampuan masyarakat dalammenghadapibencanadapatdilakukanmelaluikegiatan pembelajaran. Kegiatan pembelajar-an untuk masyarakat mengenai kebencanaan geologi melalui konsep modifikasi PRA (Participatory Rural Appraisal) dilaksanakan di Desa Hegarmanah, Keca-matan Jatinangor, Sumedang, Jawa Barat (Peta Desa Hegarmanah disampaikan di Gambar 1.). Di Desa ini terdapat wilayah Rukun Warga yang sering terkena banjir, dan terdapat wilayah yang pernah terjadi longsoran termasuk di kawasan kampus perguruan tinggi Unpad. Kondisi tanah dan kemiringan lereng di Jatinangor termasuk rawan longsor. Terdapat lapukan tanah dari batuan vulkanik dengan jenis pada umumnya $\mathrm{MH}$ atau lanau dengan plastistas tinggi, dan jenis tanah lain berupa lempung (Khoirullah et al., 2015).

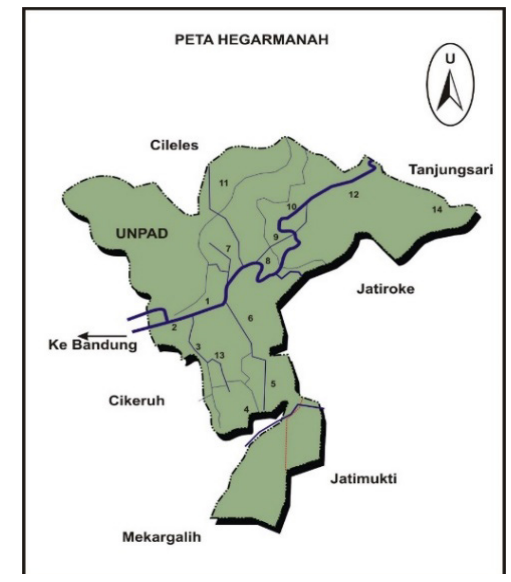

Gambar 1. Peta Desa Hegarmanah, Kecamatan Jatinangor (Anonim, 2018)

\section{METODE}

Dalam pengenalan mitigasi bencana, diperlukan pengertian beberapa istilah, yaitu risiko, bencana, bahaya dan kerentanan, serta kapasitas (BNPB, 2015; Anomim, 2017):

a) Risiko (Risk) adalah kondisi yang berpotensi menimbulkan kerugian karena bencana pada suatu wilayah dalam kurun waktu tertentu. Kerugian berupa kehilangan jiwa, kerusakan materil, hilang rasa aman, mengungsi dan gangguan lainnya.

b) Bencana adalah peristiwa atau rangkaian peristiwa yang mengancam dan mengganggu kehidupan dan penghidupan masyarakat yang disebabkan, baik oleh faktor alam dan/atau non-alam maupun faktor manusia sehingga mengakibatkan timbulnya korban jiwa manusia, kerusakan lingkungan, kerugian harta benda, dan dampak psikologis.

c) Bahaya (Hazard) merupakan kondisi alamiah atau akibat aktivitas manusia yang berpotensi menimbulkan bencana, tetapi tidak semua bahaya selalu menjadi bencana.

d) Kerentanan (vulnerability) merupakan sekumpulan situasi, sikap, perilaku individu maupun masyarakat akibat suatu keadaan (faktor fisik sosial ekonomi dan lingkungan) yang berpengaruh buruk terhadap upayaupaya pencegahan dan penanggulangan bencana. Kerentanan ini relatif dapat dilakukan perubahan.

e) Kapasitas (Capacity) merupakan kekuatan dan potensi yang dimiliki individu, keluarga, dan masyarakat yang membuat mereka mampu mencegah, mengurangi, siap-siaga, tanggap cepat, atau segera pulih dari suatu bencana atau kondisi darurat

Dalam melakukan kajian risiko bencana, pendekatan fungsi dari tiga parameter pembentuk risiko bencana, yaitu ancaman, kerentanan, dan kapasitas terkait bencana perlu diidentifikasi (BNPB, 2016). Ancaman bahaya dan kerentanan rawan bencana, akan berdampak pada risiko bencana. Risiko bencana akan menjadi bencana jika ada faktor pemicu. Pengurangan Risiko Bencana (PRB) dapat dilakukan dengan cara memperkecil kerentanan atau memperbesar kapasitas. Hal ini dapat digambarkan melalui rumus $\mathrm{R}=\mathrm{HxV} / \mathrm{C}$, risiko bencana $(\mathrm{R}$, risk) adalah bahaya $(\mathrm{H}$, hazard) terhadap kerentanan (V, vulnerability) dibagi kapasitas (C, capacity). Peningkatan kapasitas dapat mengurangi risiko. Kapasitas ini dapat ditingkatkan melalui berbagai program, sehingga masyarakat atau individu akan berpengetahuan luas di areal rawan bencana, mempunyai segala persiapan dan mempunyai perlengkapan jika ada bencana.

Jika terjadi bencana, maka selain pemerintah daerah, beberapa lembaga dapat segera dihubungi (BNPB, 2017), misalnya BPBD (Badan Penanggulangan Bencana Daerah) yang mempunyai tugas: a) menetapkan pedoman dan pengarahan sesuai dengan kebijakan pemerintah daerah dan Badan Nasional Penanggulangan Bencana terhadap usaha penanggulangan bencana yang mencakup pencegahan bencana, penanganan darurat, rehabilitasi, serta rekonstruksi secara adil dan setara; b) menetapkan standarisasi serta kebutuhan penyelenggaraan penanggulangan bencanaberdasarkan Peraturan Perundangundangan. Jika terjadi bencana geologi, PVMBG dari Badan Geologi, adalah salah satu instansi yang perlu dihubungi. Data kebencanaan geologi dihimpun di PVMBG.

Peran pentaheliks, antara pemerintah (pusat atau daerah), masyarakat, akademisi, industri dan media massa sangat penting dalam menghadapi bencana (Zakaria et al., 2018). Pemerintah dapat berperan dalam melaksanakan 
penyuluhan rutin terhadap daerah-daerah rawan bencana. Akademisi (dunia pendidikan) dapat melaksanakan pelatihan dalam memperkuat kapasitas masyarakat di wilayah rawan bencana. Aspek finansial dalam memperkuat kapasitas masyarakat di wilayah rawan bencana bisa dibantu oleh dunia industri. Media massa dapat berperan dalam memberikan informasi yang tepat dan cepat dalam upaya menanggulangi bencana, sehingga korban bencana maupun kerugian metril dapat dicegah atau dikurangi atau ditangani dengan segera. Dalam pembelajaran untuk masyarakat mengenai kebencanaan, pemerintah akan terbantu dengan adanya akademisi yang bergerak memberikan penyuluhan dengan metode yang tepat. Pembelajaran kebencanaan adalah suatu upaya memperkuat kapasitas indivisu maupun masyarakat dalam menghadapi bencana dan mengurangi risiko bencana. Untuk hal tersebut, diperlukan sarana dan prasarana sebagai penunjang agar pembelajaran tepat sasaran dan dapat diterima dalam tempo yang singkat.

\section{Aplikasi Android}

Hampir semua individu dalam masyarakat sudah mengenal telepon genggam (HP, handphone) atau bahkan memilikinya. Beberapa aplikasi dalam handphone berupa smartphone dengan sistem Android (Gambar 2), dapat dimanfaatkan untuk pembelajaran masyarakat dalam mengenal wilayahnya, mengenal berbagai kebencanaan geologi, mengetahui upaya pencegahan risiko bencana, serta mendapatkan informasi yang selalu baru. Aplikasi tersebut dapat diunduh dan disimpan dalam handphone. Informasi kebencanaan dapat disampaikan sesuai kejadiannya. Berikut ini adalah beberapa aplikasi Andorid yang berhubungan dengan kebencanaan:

1. MAGMA INDONESIA (Magma, 2015), merupakan singkatan dari Multiplatform Application for Geohazard Mitigation and Assessment in Indonesia, dikembangkan oleh Pusat Vulkanologi dan Mitigasi Bencana Geologi. Aplikasi ini memberikan notifikasi kejadian semua bencana geologi di Indonesia, misalnya bencana letusan gunung api dan informasi untuk penerbangan yang berkaitan dengan debu letusan yang dapat mengganggu pesawat terbang. Selain itu, dapat ditampilkan pula petapeta kebencaan geologi di Indonesia.

2. InaRISK Personal (InaRISK, 2017), dikembangkan oleh Badan Nasional Penanggulangan Bencana (BNPB). Data peta tahun 2018 didukung oleh Google. Aplikasi ini memberikan informasi kondisi risiko kebencaaan di sekitar tempat pengguna berada. Aplikasi ini menggunakan hasil kajian yang dibangun oleh BNPB bersama Kementerian/Lembaga terkait serta dukungan organisasi kebencanaan yang ada di Indonesia.

3. RSOE-EDIS (2013), memberikan informasi segala peristiwabencana diseluruhbelahan dunia dikembangkan oleh National Association of Radio Distress-Signaling and Infocommunications, \& Emergency and Disaster Informations Services (EDIS), Budapest, Hongaria. Aplikasi ini didukung oleh GoogleEarth terkini. Tidak hanya bencana geologi (gerakan tanah, gempa, tsunami, dan letsan gunungapi), aplikasi ini memberikan informasi kejadian bencana lainnya seperti kebakaran, kecelakaan nuklir, topan, banjir, dan lain.lain.

4. Info BMKG (BMKG, 2018), dikembangkan oleh Badan Meteorologi, Klimatologi dan Geofisika. Aplikasi ini memberikan informasi iklim, cuaca dan kejadian gempa dam tsunami di Indonesia.
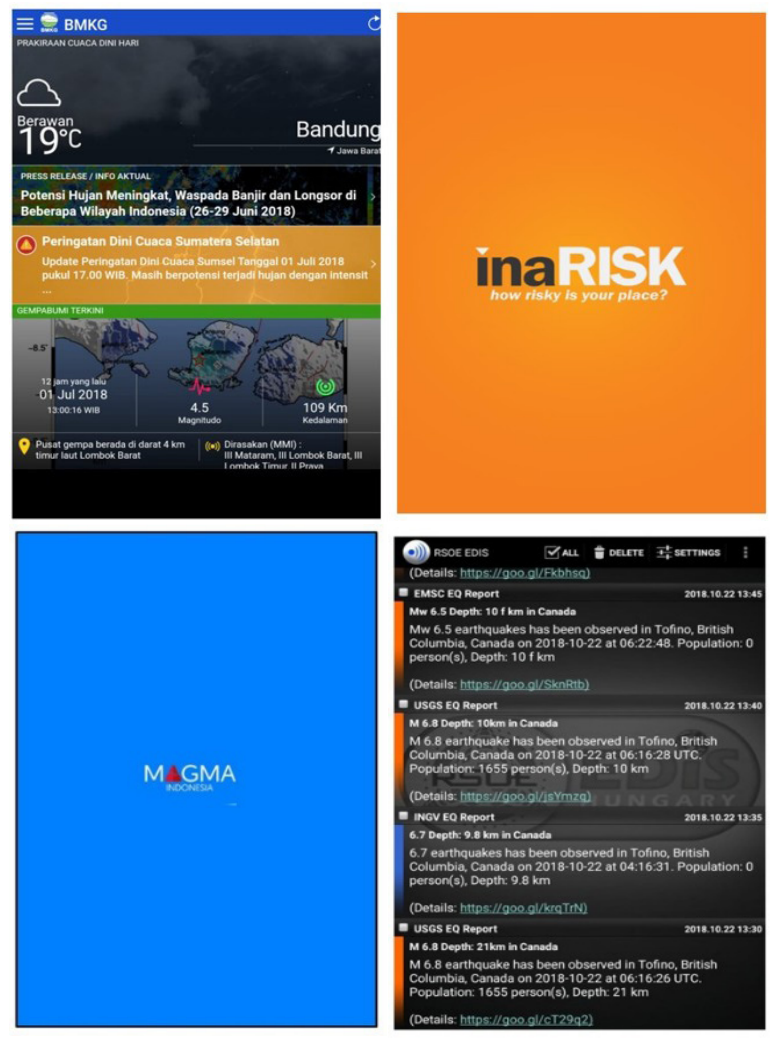

Gambar 2. Berbagai aplikasi sistem Android yang berhubungan dengan kebencanaan, berurutan dari kiri ke kanan, tampilan Info BKMG, InaRISK, MAGMA, dan RSDOE

\section{Modifikasi PRA ( Participatory Rural Apraisal )}

Metode yang digunakan dalam pemberdayaan masyarakat adalah melalui modifikasi konsep Participation Rural Appraisal (PRA). Perbedaan dengan konsep PRA konvensional adalah dalam hal peran masyarakat, peran orang luar, informasi dan cara penyampaian informasi (Tabel 1). Metode modifikasi PRA ini bertujuan untuk pencapaian target secara cepat dan tepat dengan membangkitkan kemampuan masyarakat setempat (Zakaria et al., 2018). Metode ini juga bertujuan memfasilitasi secara partisipatif agar masyarakat dapat diberdayakan dalam menghadapi berbagai aspek yang berhubungan dengan kebencanaan. Dosen dan mahasiswa bertindak sebagai mitra, fasilitator sekaligus penyuluh. Kegiatan dilakukan dalam suatu seminar dan penyuluhan mengenai pembelajaran tersebut.

\section{Teknik Penyampaian Materi Pembelajaran}

Penyampaian materi pembelajaran dilaksanakan melalui kegiatan penyuluhan dan pembelajaran dalam seminar KKN-PPM Mahasiswa Unpad untuk masyarakat 
Desa Hegarmanah di Bale Desa Hegarmanah, Jatinangor, dengan pembicara dari dosen pembimbing lapangan. Seminar berjudul Pembelajaran untuk masyarakat mengenai kebencanaan geologi melalui konsep modifikasi PRA (Participatory Rural Appraisal).

Tabel 1. Perbedaan konsep PRA dan Modifikasi PRA (Modifikasi dari Zakaria et al., 2018)

\begin{tabular}{lll}
\hline \multicolumn{1}{c}{ Sifat proses } & \multicolumn{1}{c}{ PRA } & \multicolumn{1}{c}{ Modifikasi PRA } \\
\hline Mode & $\begin{array}{l}\text { Berbagi - } \\
\text { pemberdayaan }\end{array}$ & $\begin{array}{l}\text { Berbagi informasi dan } \\
\text { pemberdayaan }\end{array}$ \\
Peran orang luar & Fasilitator & $\begin{array}{l}\text { Mitra, fasilitator, } \\
\text { sekaligus peneliti }\end{array}$ \\
Informasi & $\begin{array}{l}\text { Orang lokal } \\
\text { atau masyarakat } \\
\text { desa }\end{array}$ & $\begin{array}{l}\text { Dosen, mahasiswa dan } \\
\text { masyarakat pedesaan } \\
\text { (atau orang lokal) }\end{array}$ \\
Metode & $\begin{array}{l}\text { Masyarakat lokal } \\
\text { menyampaikan } \\
\text { informasi yang } \\
\text { diketahuinya } \\
\text { untuk diarahkan } \\
\text { oleh fasilitator } \\
\text { dalam menangani } \\
\text { masalah di } \\
\text { desanya. }\end{array}$ & $\begin{array}{l}\text { Masyarakat desa } \\
\text { menyampaikan } \\
\text { informasi yang } \\
\text { diketahuinya, ditambah } \\
\text { dengan informasi yang } \\
\text { didapat dari luar (dari } \\
\text { dosen dan mahasiswa } \\
\text { atau peneliti lainnya) } \\
\text { sehingga dapat berbagi } \\
\text { informasi dan bersama- } \\
\text { sama mencari tahu } \\
\text { penanganan masalah. }\end{array}$ \\
\hline
\end{tabular}

Dalam kegiatan ini beberapa perangkat untuk audio visual diperlukan seperti sound system dan LCD Projector. Pembicara menyiapkan materi pembelajaran dalam laptop dengan beberapa perangkat lunak yang diperlukan. Peserta membawa smartphone masing-masing. Dalam kegiatan tersebut dilaksanakan pembelajaran sekaligus pemberian informasi mengenai kondisi Jatinangor, informasi mengenai bencana geologi (gempabumi, letusan gunungapi, tsunami, gerakan tanah), informasi mengenai Penanganan Risiko Bencana dan istilah-istilah dalam kebencanaan (bahaya, bencana, risiko, kerentanan, kapasitas). Selain itu, pembelajaran dan pemberian informasi dilaksanakan sekaligus sebagai penyuluhan.

Dalam kegiatan tersebut disampaikan mengenai pentingnya media komunikasi dan informasi, serta pemanfaatan smartphone. Dalam satu sesi materi dibahas beberapa aplikasi untuk handphone sistem Android yang berhubungan dengan kebencanaan, serta diperagakan cara mengunduh beberapa aplikasi Android tersebut melalui smart phone.

Pada kegiatan ini diadakan pre-test sebelum masuk ke materi pembicaraan dalam seminar, dan kemudian kembali diadakan test berupa post-test yang dilaksanakan setelah semua materi seminar disampaikan kepada peserta. Kedua test tersebut akan dianalisis dan dibahas untuk mengetahui sejauhmana perubahan peserta dalam menyerap informasi yang disampaikan saat seminar, penyuluhan dan pembelajaran.

\section{HASIL DAN PEMBAHASAN}

Peserta diminta untuk melaksanakan test sebelum dan sesudah acara. Test dilaksanakan dengan sepuluh soal yang perlu dijawab secara jujur oleh para peserta. Berikut ini adalah analisis dan pembahasan atas jawaban dari sepuluh Soal Pre-Test dan Post-Test tersebut.

Pertanyaan pertama adalah mengenai pengetahuan jenis bencana geologi di Indonesia. Jenis bencana geologi yang disebutkan oleh PVMBG (Pusat Vulkanologi dan Mitigasi Bencana Geologi), yaitu gempabumi, letusan gunungapi, tsunami, dan gerakan tanah (longsor, termasuk gerakan tanah adalah likuifaksi, amblesan, dll). Pada kondisi pre-test ini, beberapa peserta tidak mengetahuinya. Terdapat $18 \%$ peserta tidak mengetahui jenisjenis bencana geologi di Indonesia pada saat pre-test dilaksanakan. Setelah presentasi penyuluhan dilaksanakan, maka dilaksanakan post-test . Terdapat $100 \%$ peserta telah mengetahui jenis-jenis bencana geologi di Indonesia.

Pertanyaan kedua adalah mengenai pengetahuan kebencanaan di wilayah Rukun Warga masin-masing. Pada saat pre-test maupun post test, semua peserta (100\%) mengetahui jenis-jenis bencana yang ada di sekitar wilayahnya. Beberapa bencana yang pernah terjadi di wilayah peserta adalah longsor, gempabumi, dan banjir. Di beberapa wilayah Rukun Warga, diketahui sering terjadi banjir bila hujan tiba.

Pertanyaan ketiga adalah mengenai pengetahuan tentang perbedaan antara risiko dan bencana secara umum. Sebelum pelaksanaan seminar dilaksanakan, terdapat $91 \%$ peserta yang mengetahui perbedaan tersebut, namun ada $9 \%$ yang tidak bisa membedakan antara risiko dan bencana. Setelah pelaksanaan seminar, presentasi dan penyuluhan, maka $100 \%$ warga peserta seminar mengetahui perbedaan antara risiko dan bencana.

Pertanyaan keempat adalah mengenai pengetahuan tentang perbedaan antara kerentanan dan bahaya secara umum. Hasil pre-test, sebelum pelaksanaan seminar, diketahui terdapat $77 \%$ peserta yang mengetahui apa yang disebut dengan kerentanan dan bahaya, namun ada $23 \%$ peserta yang tidak bisa membedakan antara kerentanan dan bahaya. Setelah pelaksanaan seminar, dilaksanakan post-test, maka terdapat $100 \%$ warga peserta seminar telah mengetahui perbedaan antara kerentanan dan bahaya.

Pertanyaan kelima adalah alur informasi pelaporan jika ada bencana. Sebelum seminar, $86 \%$ peserta mengetahui alur pelaporannya, sebanyak $14 \%$ tidak mengetahui. Setelah seminar, informasi mengenai alur pelaporan jika ada bencana, bisa siketahui oleh $100 \%$ peserta.

Pertanyaan keenam mengenai cara penyampaian informasi dalam penyuluhan oleh pemerintah kepada masyarakat. Sebelum seminar, sebanyak $64 \%$ peserta mengetahui cara tersebut, sedangkan 36\% tidak mengetahui. Seteah seminar presentai dan penyuluhan, maka $100 \%$ peserta dapat mengetahui cara penyampaian informasi yang tepat dalam kegiatan penyuluhan oleh pemerintah kepada masyarakat.

Pertanyaan ketujuh mengenai keyakinan peserta bahwa peran pembelajaran kebencanaan geologi dapat mendukung kesejahteraan rakyat. Pada pre-test terdapat 86 $\%$ peserta yakin bahwa pembelajaran dapat meningkatkan 
kesejahteraan, namun sebanyak $14 \%$ tidak mengetahui. Pada post-test sebanyak $100 \%$ peserta yakin bahwa pembelajaran kebencanaan geologi dapat mendukung kesejahteraan rakyat.

Pertanyaan kedelapan mengenai perlunya metode penyuluhan yang baru agar materi penyuluhan bisa cepat dan tepat sasaran. Pada saat pre-test maupun post test, semua peserta $(100 \%)$ merasakan perlunya suatu metode baru dalam penyuluhan agar masyarakat mudah menerima informasi kebencanaan dan mengetahui penanganannya. Metode baru tersebut diharapkan dapat melibatkan semua peserta dan penyuluh atau pelatih, dengan metode baru tersebut, peserta dapat dibangkitkan kemampuan analisis mengenai wilayahnya sesuai dengan kapasitasnya. Peserta dapat diberikan penyuluhan dengan model seminar dan kemudian dapat dilatih ketrampilan sesuai dengan thema penyuluhannya.

Pertanyaan kesembilan mengenai aplikasi dalam smart-phone sistem Android. Sebelum penyampaian informasi, terdapat $14 \%$ saja yang mengetahui manfaat smartphone mengenai kebencanan geologi. Pengetahuan peserta meningkat, terdapat $91 \%$ mengetahui aplikasi kebencaan dalam smartphone setelah penyampaian informasi dalam seminar ini. Sisa 9\% masih belum mengetahui. Hal ini bisa terjadi karena sebagian hand-phone tidak semua mendukung aplikasi yang disampaikan saat seminar.

Pertanyaan kesepuluh mengenai pentingnya informasi kebencanaan dalam kehidupan sehari-hari. Sebelum seminar, ada $18 \%$ yang tidak tahu manfaat informasi. Setelah seminar $100 \%$ mengetahui manfaat informasi tersebut. Berikut hasil lengkap pada Tabel 2.

Secara keseluruhan, terjadi peningkatan pengetahuan secara umum dari peserta sebelum dan setelah kegiatan seminar, penyuluhan dan pembelajaran dilaksanakan. Hanya pada pertanyaan kesembilan, masih ada 9\% yang belum mengetahui aplikasi dalam smatphone sehubungan dengan peserta tidak membawa handphone yang sesuai dengan smartphone sistem Android.

Tabel 2. Hasil pre-test dan post-test

\begin{tabular}{|c|c|c|c|c|c|}
\hline \multirow{7}{*}{ No. } & \multirow{7}{*}{ Pertanyaan } & \multicolumn{4}{|c|}{ Jawaban pertanyaan } \\
\hline & & \multirow{5}{*}{ Ya } & Tidak & & Tidak \\
\hline & & & Tahu & & Tahu \\
\hline & & & / & Ya & / \\
\hline & & & Tidak & & Tidak \\
\hline & & & perlu & & Perlu \\
\hline & & \multicolumn{2}{|c|}{ Pre Test $(\%)$} & \multicolumn{2}{|c|}{ Pre Test $(\%)$} \\
\hline 1 & $\begin{array}{l}\text { Apakah Anda } \\
\text { mengetahui jenis- } \\
\text { jenis bencana } \\
\text { geologi di Indonesia? }\end{array}$ & 82 & 18 & 100 & 0 \\
\hline 2 & $\begin{array}{l}\text { Apakah Anda } \\
\text { mengetahui jenis-jenis } \\
\text { bencana di sekitar } \\
\text { wilayah Anda? }\end{array}$ & 100 & 0 & 100 & 0 \\
\hline 3 & $\begin{array}{l}\text { Apakah Anda } \\
\text { mengetahui dan } \\
\text { dapat membedakan } \\
\text { antara Resiko dan } \\
\text { Bencana? }\end{array}$ & 91 & 9 & 100 & 0 \\
\hline
\end{tabular}

Apakah Anda 77 23 100 chan dan antara Kerentanan dan Bahaya?

Jika ada bencana geologi, apakah Anda mengetahui kemana saja harus melaporkannya ?

6 Apakah Anda mengetahui cara penyampaian informasi dalam penyuluhan oleh Pemerintah kepada masyarakat?

7 Apakah Anda yakin bahwa pembelajaran mengenai kebencanaan geologi dapat mendukung kesejahteraan rakyat?

8 Perlukah suatu metode penyuluhan baru agar masyarakat pedesaan mudah menerima informasi kebencanaan dan mengetahui penanganannya?

9 Apakah Anda mengetahui beberapa aplikasi system Android (MAGMA, InaRISK, RSOE, dan Info BMKG) mengenai kebencanaan yang dapat dipasang di Hand Phone?

10 Apakah Anda mengetahui manfaat informasi mengenai kebencanaan dalam kehidupan sehari-hari?

$\begin{array}{llll}86 & 14 & 100 & 0 \\ & & & \\ & & & \\ & & & \\ & 100 & 0\end{array}$

\section{SIMPULAN}

Dari kegiatan tersebut dapat disimpulkan bahwa pembelajaran untuk masyarakat mengenai kebencanaan geologi melalui konsep modifikasi $P R A$, dapat dilaksanakan dengan cepat dan tepat, namun pelaksanaan yang singkat tersebut harus melalui berbagai persiapan sebelumnya yang memerlukan waktu cukup lama. Kegiatan ini menunjukkan hasil yang cukup berarti dengan terjadinya perubahan dalam pengetahuan para peserta sebelum dan sesudah mengikuti kegiatan. Hal ini diketahui dari hasil test sebelum dan sesudah pelaksanaan kegiatan seminar, penyuluhan, dan pembelajaran. Terhadap pengetahuan aplikasi Android, masih terdapat 9\% tidak tepat sasaran. 
Ini akibat peserta tidak membawa smartphone sistem Android. Untuk melaksanakan kegiatan berupa seminar dengan penyuluhan dan pembelajaran yag serupa seperti ini, maka persyaratan untuk peserta perlu disampaikan sebelumnya dalam undangan agar kegiatan sesuai dan tepat sasaran.

\section{UCAPAN TERIMAKASIH}

Ucapan terima kasih disampaikan kepada Direktur Riset, Pengabdian kepada Masyarakat dan Inovasi (DRPMI) yang telah memberikan kesempatan untuk melaksanakan penelitian dan Pengabdian Pada Masyarakat (PPM) di Desa Hegarmanah, Jatinangor dengan Nomor Kontrak : 1925/UN6.P/PM/2018 Tanggal 5 Maret 2018, melalui dana Hibah Interal Unpad.

\section{DAFTAR PUSTAKA}

Anonim. (2017). Undang-Undang Republik Indonesia Nomor 24 tahun 2017 tentang Penanggulangan Bencana.

Anonim. (2018). Peta Desa Hegarmanah, Kecamatan Jatinangor, http://2.bp.blogspot. com/-u9v64-MKRu0/UXQcNRrCldI/ AAAAAAAAAVw/8r9kZS14GWg/s 1600/ Peta+Hegarmanah+JPG.jpg, diakses tanggal 12 November, pukul 12:20

BMKG. (2018). Info Badan Meterologi, Klimatologi dan Geofisika (BMKG), Cuaca, Iklim, dan gempabumi Indonesia, situs: https://play.google. com/store/apps/details?id=com.Info_BMKG, diakses tanggal 16 November 2017, pukul 11:10

InaRISK. 2018, InaRISK personal. Diakses pada tanggal 16 November 2017, pukul 13:40, alamat situs https:/play.google.com/store/apps/ details?id=com.inarisk.bnpb

BNPB. (2013). Indeks Risiko Bencana Indonesia (IRBI) 2013, ISBN : 978-602-70256-0-8, Direktorat PRB, Deputi Bidang Pencegahan dan Kesiapsiagaan, BNPB, 318 hal.

BNPB. (2016). Risiko Bencana Indonesia, Direktorat Pengurangan Risiko Bencana, Deputi Bidang Pencegahan dan Kesiapsiagaan, BNPB, 218 hal.
BNPB. (2017). Buku saku: tanggap,tangkas, tangguh menghadapi bencana, Pusat Data, Informasi dan Humas, Badan Nasional Penanggulangan Bencana, 75 hal.

Fauzielly, L., Jurnallah, L., Jihadi, L.H., Aditio, M., Ramadhan, T.H., dan Mufti, I.J., 2018, Sosialisasi mitgasu bencana longsor di daerah Hambalang, Kecamatan Citerep, Kabupaten Bogor, Dharmakarya: Jurnal Aplikasi Ipteks untuk Masyarakat Vol. 7, No. 1, Maret 2018: 11 - 13

Khoirullah, N., Putra, Y.P., Frini, G.G., Sophian, I., Zakaria, Z. (2015). Engineering Geological Mapping in Jatinangor Area. Proceedings of 2nd International Conference and The 1st Joint Conference Faculty of Geology Universitas Padjadjaran - Faculty of Science and Natural Resources Universiti Malaysia Sabah, Sep. 29, 2015, Bandung, pp. 253258

Magma Indonesia. 2015. Magma Indonesia (C 2015-2017 PVMBG. [v0.1.3 Alpha] Privacy Policy, https:// play.google.com/store/apps/details? $\mathrm{id}=\mathrm{com}$. magma.pvmbg.magmaindonesia, diakses 16 November 2017, pukul 13:52,

RSOE EDIS. (2013). RSOE EDIS Notifer Lite. (C) 2013, The National Association of Radio Distress-Signalling and Info Communications (RSOE) \& Emergency and Disaster Information Service (EDIS). Diakses tanggal 16 November 2017, pukul 18:33, alamat situs: https://play. google.com/store/apps/details?id=org.rsoe. android.edis_pms

Zakaria, Z., Sophian, R.I., \& Khoirullah, N. (2018). Modifikasi konsep Participatory Rural Appraisal untuk pembekalan Kuliah Kerja Nyata Mahasiswa di Jawa Barat, Indonesia, Dharmakarya: Jurnal Aplikasi Ipteks untuk Masyarakat Vol. 7, No. 1 Maret 2018, hal. 38-45, ISSN :1410 - 5675

Zakaria, Z. (2007). Aplikasi tektonik lempeng dalam sumber daya mineral, energi dan kewilayahan, Bulletin of Scientific Contribution. Vol. 5, No. 2, April 2007: 123-131 